\title{
Socially cued smoking in bars, nightclubs, and gaming venues: a case for introducing smoke-free policies
}

\author{
L Trotter, M Wakefield, R Borland
}

Tobacco Control 2002;11:300-304

See end of article for authors' affiliations

Correspondence to: Lisa Trotter MA, Research and Evaluation Manager, 1 Rathdowne Street, Carlton Victoria 3053, Australia;

Lisa.Trotter@cancervic.org.au

Received 5 September 2002 and revision requested 3 July 2002 Accepted 8 September 2002

\begin{abstract}
Objective: To assess smokers' perceived effects of smoking bans in bars, nightclubs, and gaming venves on their smoking behaviour.

Design: Cross sectional structured interview telephone survey of a random sample of smokers. Setting: Population survey in Victoria, Australia.

Participants: The sample comprised 597 smokers and analyses were conducted on 409 smokers who reported patronising bars, nightclubs or gaming venues at least monthly.

Outcome measures: Two outcomes studied were socially cued smoking and readiness to quit as a result of restrictions on smoking in social venues. Respondents were identified as socially cued smokers if they reported attending bars, nightclubs or gaming venues at least monthly and said that they smoke more in these venues. The potential influence of bans in social venues on readiness to quit was measured by asking respondents if they would be more or less likely to quit smoking if smoking were banned in hotels, licensed bars, gaming venues, and nightclubs.

Results: Of all adult smokers, $69 \%$ attended bars, nightclubs or gaming venues at least monthly. Of these smokers, $70 \%$ reported smoking more in these settings (socially cued smokers) and 25\% indicated they would be likely to quit if smoking were banned in social venues. Compared to smokers not likely to quit if there were bans, smokers likely to quit were more likely to be socially cued (odds ratio (OR) 2.64), to be contemplating or preparing to quit (OR 2.22), to approve of bans in social venues (OR 2.44), and to be aged under 30 years (OR 1.73). Compared with smokers not socially cued, socially cued smokers were more likely to be under the age of 30 years (OR 6.15), more likely to believe that there is a safe level of cigarette consumption (OR 2.25), and more likely to have previously made a quit attempt (OR 2.60).

Conclusions: These findings suggest that bans on smoking in bars, nightclubs, and gaming venues could reduce cigarette consumption and increase quitting among smokers who frequently patronise these settings. These beneficial effects are likely to be strongest among younger smokers.
\end{abstract}

Ir he effect of restrictions on smoking in the workplace and at home has been well documented in the literature, but there has been little study of the effects of smoking policies on smoking behaviour in social settings such as bars, nightclubs, and gaming venues ("social venues"). Smoking restrictions in the workplace and at home have been found to contribute to reduced consumption, ${ }^{12}$ intentions to quit, relapse prevention, ${ }^{3}$ and possibly increased cessation, ${ }^{45}$ as well as send a message that smoking is socially unacceptable. ${ }^{6}$ Although the main purpose of smoking restrictions in public places is to reduce exposure to environmental tobacco smoke, it may also have the effect of reducing tobacco consumption and encouraging quitting.

The literature on situational influences on smoking relapse supports the notion that restrictions on smoking in venues such as bars and nightclubs may remove the social pressure to smoke. Social situations exert a powerful influence on smoking relapse, with around a quarter of relapse crises occurring in settings such as bars and restaurants. ${ }^{78}$ Shiffman $^{7}$ explained this as being caused by exposure to other smokers-involving both direct offers of cigarettes and indirect pressure through observation of other smokers-as well as the influence of alcohol weakening willpower to avoid smoking.

Another possible consequence of restrictions on smoking in social venues is the prevention or delay of smoking uptake. A relatively new line of evidence has begun to suggest that bans in public places may reduce smoking among young people. ${ }^{9}$ Given that the people who patronise social venues are mostly young, smoking bans in these settings might also serve to interrupt the process of progression from experimentation with smoking to long term tobacco dependence. Although many of the factors that influence the uptake of smoking are present at a very young age and school aged children are often targeted for intervention, the period after leaving school has been identified as a critical time for transition to regular smoking. ${ }^{11}{ }^{12}$ The role of situational influence may be greatest early on when smoking among young people is not so influenced by addiction. ${ }^{13}$

Recreational venues that allow smoking expose young people to contexts in which smoking may be viewed as the norm. This may encourage their progression to more regular smoking. Pierce and others ${ }^{14}{ }^{15}$ found that exposure to smokers distinguished adolescents who progressed to established smoking from those who remained experimenters. Further, the tobacco industry is actively promoting tobacco in bars and nightclubs which may contribute to smoking uptake and relapse back to smoking for those trying to quit. Studies of tobacco industry documents ${ }^{16}{ }^{17}$ have found that bar promotions are generally targeted at a young adult audience and characterise cigarettes as being part of a glamorous lifestyle that includes attendance at nightclubs and bars. This finding is consistent with the evidence from a recent study of tobacco promotions that found a large increase in entertainment focused promotions-mostly bar-club and event promotions. ${ }^{18}$

Many jurisdictions in Australia, Canada, the USA, and other countries have legislated smoking restrictions in public places. With few exceptions, smoking policies apply to restaurants but do not extend to bars, nightclubs or gaming venues. The potential effects of smoking restrictions in bars, nightclubs, 
and gaming venues on smoking behaviour may be better understood by examining the behaviour, beliefs, and opinions of smokers who frequently patronise these venues.

\section{METHOD}

Data were drawn from a telephone survey conducted in November 2000 in the state of Victoria, Australia. The survey was conducted by a large market research company. Only respondents aged 18 years and over were interviewed. A total of 417 smokers were interviewed from a random sample of 2000 Victorians, of which smokers comprised $21 \%$. A survey of 1000 Victorians conducted by another company using the same method and questionnaire was used to boost the number of smokers. Only smokers were interviewed and they comprised $18 \%$ of this sample $(n=180)$. Thus, 597 smokers were interviewed in total.

The sampling frame for the survey was derived from a current CD-ROM telephone directory database. The data collection occurred over a period of 10 days, including weekend days and weekday evenings. Response rates have been calculated as the proportion of all telephone contacts made that resulted in a useable interview. There were 2000 useable interviews (31\%) out of 6488 numbers contacted and, for the boost sample, there were 1001 useable interviews $(46 \%)$ out of 2173 numbers contacted. Part of the reason for the differential response rates may have been that the booster survey was shorter for non-smokers, comprising only a question on tobacco use. There was no other obvious reason for the difference in response rates; however, a comparison of frequency distributions between survey samples showed no differences in sample composition.

\section{Variables}

Smoking status was measured using questions developed by a national expert committee convened by the Australian Institute of Health and Welfare. ${ }^{19}$ "Smokers" were defined as those who reported current smoking either "daily", "weekly" or "less than weekly". "Socially cued smokers" were defined as smokers who reported going to either bars (described as hotel or licensed bar), nightclubs or gaming venues (described as gaming venue to play poker machines) ("social venues") at least monthly and reported that they smoke more in these venues. "Not socially cued smokers" were defined as smokers who go to social venues at least monthly and do not report that they smoke more in these venues.

Smoking behaviour was described in terms of consumption $^{20}$ ( $\leqslant 5$ or $>5$ cigarettes per day) and time to first cigarette for the day ${ }^{21}$ (first cigarette for the day $\leqslant 29$ or $>29$ minutes after waking). These variables were combined to provide an indication of nicotine dependence. Those considered addicted either smoked more than five cigarettes per day or smoked their first cigarette of the day less than 30 minutes after waking. Smokers were designated as being in precontemplation if they indicated that were not planning to quit in the next six months ${ }^{22}$ and smokers who did so respond were designated as being in contemplation/preparation.

To measure the potential influence of bans in social venues on readiness to quit, respondents were asked "if smoking were banned in hotels, licensed bars, gaming venues and nightclubs, would you be more or less likely to quit smoking altogether?" with respondents able to indicate "more likely", "less likely" or "no difference". Respondents were also asked "do you think that there is a safe number of cigarettes that you can smoke before it affects your health?".

Respondents were asked if they approve or disapprove of the government banning smoking in bars, nightclubs or gaming venues. A variable was constructed that combined responses for each of these variables into two categories: "approval/neither approve or disapprove" or "disapproval". Demographic information was also collected, including age
Table 1 Frequency distribution of patronage at social venues $(n=597)$

\begin{tabular}{lccc}
\hline & Bars (\%) & $\begin{array}{l}\text { Nightclubs } \\
(\%)\end{array}$ & $\begin{array}{l}\text { Gaming } \\
\text { venues (\%) }\end{array}$ \\
\hline More than weekly & 13.4 & 2.7 & 2.8 \\
At least once a week & 16.6 & 5.4 & 5.4 \\
At least once every 2 weeks & 11.6 & 5.2 & 5.4 \\
At least once a month & 18.1 & 8.2 & 9.7 \\
Less than once a month & 25.3 & 24.5 & 31.0 \\
Never & 14.6 & 54.1 & 45.7 \\
Don't know & 0.5 & 0 & 0 \\
\hline
\end{tabular}

( $\leqslant 29$ or $>29$ years), sex, and education (tertiary education "more" or secondary school and lower "less").

\section{Statistical analyses}

All analyses were undertaken using the statistical package SPSS Version 10.0.7. Conventional $\chi^{2}$ tests were used to test for associations between likelihood of quitting if bans were in place, type of smoker (socially cued or not socially cued), and the variables of interest. A significance level of 0.05 was adopted. All variables were initially included in logistic regression analysis predicting key outcomes. Because of missing data, this led to a reduction in sample size, so the analyses were repeated using only the significantly related variables (and those almost significant) to maximise sample size. In no case did this affect the variables included and the data reported are on the maximal sample.

A comparison of the age and sex distribution for the survey with Australian Bureau of Statistics population estimates for Victoria in $2000^{23}$ indicated that the sample was representative of the population except that women (survey 59.4\% $v$ population $50.1 \%$ ) and people aged 60 years and older ( $19.8 \% v 12.1 \%$ population) were over represented in the sample. The sample was weighted by age and sex according to population census data to estimate the proportion of smokers in Victoria who attend social venues monthly, smoke more in these venues, and are likely to quit if there were bans in social venues. However, weighting procedures were not used in the $\chi^{2}$ and logistic regression analyses.

\section{Research questions}

We sought to determine: (1) to what extent smokers who frequently patronised social venues were likely to quit smoking if there were bans in social venues; (2) the characteristics of smokers who indicated they were likely to quit if there were bans in these social venues; and (3) the characteristics of social smokers.

\section{RESULTS}

The proportion of smokers in Victoria who attend social venues monthly was estimated to be $69.4 \%$ (95\% confidence interval (CI) $65.5 \%$ to $73.2 \%$ ). Of this group, $70.1 \%$ (95\% CI $65.5 \%$ to $74.6 \%$ ) smoke more in social venues and $25.4 \%$ (95\% CI $21.1 \%$ to $29.9 \%$ ) are likely to quit if smoking were banned in social venues. A criterion used to select the sample for further analyses was frequency of patronage at social venues. As can be seen in table 1, bars were visited at least monthly by $60 \%$ of smokers, nightclubs were visited at least monthly by $21 \%$ of smokers, and gaming venues were visited at least monthly by $23 \%$ of smokers. The 409 (69\%) smokers who reported at least monthly patronage of at least one of these venues constituted the sample for the remainder of the analyses.

Table 2 shows the demographic characteristics, smoking behaviour, and opinions of at least monthly and less than 
Table 2 Characteristics of those who patronise social venues at least monthly and less than monthly

\begin{tabular}{|c|c|c|c|c|}
\hline \multirow[b]{2}{*}{ Percentage of total $\dagger$} & \multirow{2}{*}{$\begin{array}{l}\text { n } \\
597\end{array}$} & \multicolumn{3}{|c|}{$\begin{array}{l}\text { At least monthly Less than } \\
\begin{array}{ll}(n=409) \quad \text { monthly }(n=188 p \text { Value }\end{array}\end{array}$} \\
\hline & & 68.5 & 31.5 & \\
\hline Age $(\%<30)$ & 594 & 33.5 & 9.0 & $0.000 * * *$ \\
\hline Sex ( $\%$ female) & 597 & 49.1 & 69.7 & $0.000 * * *$ \\
\hline Education (\% less) & 595 & 50.5 & 63.1 & $0.004 * *$ \\
\hline Nicotine dependence ( $\%$ yes) & 597 & 49.9 & 54.8 & 0.265 \\
\hline Made quit attempts (\% yes) & 591 & 79.3 & 81.2 & 0.588 \\
\hline Safe number of cigarettes (\% yes) & 597 & 14.4 & 12.2 & 0.470 \\
\hline Bans (\% approve/neither) & 579 & 64.7 & 75.8 & $0.008 * *$ \\
\hline Stage of change (precontemplation) & 597 & 51.8 & 58.5 & 0.128 \\
\hline
\end{tabular}

Table 3 Differences between those likely or not likely to quit if bans

\begin{tabular}{|c|c|c|c|c|c|c|}
\hline & $\mathrm{n}$ & $\begin{array}{l}\text { Likely } \\
(n=100)\end{array}$ & $\begin{array}{l}\text { Not likely } \\
(n=309)\end{array}$ & p Value & Odds ratio $(95 \% \mathrm{Cl})$ & $\mathrm{p}$ Value \\
\hline Percentage of total $\dagger$ & 409 & 24.4 & 75.5 & & & \\
\hline Age $(\%<30$ years $)$ & 395 & 47.0 & 29.2 & $0.001 * *$ & 1.73 (1.03 to 2.88$)$ & $0.037 * *$ \\
\hline Sex (\% female) & 398 & 45.0 & 50.7 & 0.326 & & \\
\hline Education (\% less) & 397 & 49.0 & 50.5 & 0.795 & & \\
\hline Nicotine dependence (\%yes) & 398 & 44.0 & 52.3 & 0.148 & & \\
\hline Made quit attempts (\% yes) & 394 & 84.8 & 77.3 & 0.109 & & \\
\hline Safe number of cigarettes (\% yes) & 398 & 19.0 & 12.8 & 0.123 & & \\
\hline Socially cued smoker (yes) & 398 & 85.0 & 64.8 & $0.000 * * *$ & 2.64 (1.40 to 5.00$)$ & $0.003 * *$ \\
\hline Bans (\%approve/neither) & 388 & 79.8 & 58.8 & $0.000 * * *$ & 2.44 (1.39 to 4.30$)$ & $0.002 * *$ \\
\hline Stage of change (precontemplation) & 398 & 35.0 & 56.4 & $0.000 * * *$ & 2.22 (1.35 to 3.67$)$ & $0.002 * *$ \\
\hline
\end{tabular}

†This differs from the level reported in the text because this is an unweighted figure.

${ }^{* *} p<0.05$

$* * * p<0.001$

$\mathrm{Cl}$, confidence interval.

monthly patrons. The results show that smokers who patronise social venues at least monthly were more likely to be younger, male, have higher educational attainment, and lower approval of bans than smokers who patronise social venues less than monthly.

Factors associated with intention to quit smoking if social venues became smoke-free were investigated (table 3 ). The results show that smokers who are likely to quit if there were bans in social venues were likely to be younger, socially cued (that is, smoke more in social venues), express greater approval of bans, and be contemplating or preparing to quit, compared to those not likely to quit if there were bans.

Variables found to be significantly associated with an increased perceived likelihood of quitting in the bivariate analyses were entered into a logistic regression analysis and 386 cases were included in the final analysis. Table 3 shows a model containing four variables which provide a significant fit to the data $\left(\chi^{2}=44.16, \mathrm{df}=4, \mathrm{p}=0.000\right)$. Compared to smokers not likely to quit in response to smoking bans, smokers likely to quit were two and a half times more likely to be socially cued (that is, to smoke more in these venues), twice as likely to be contemplating or preparing to quit, twice as likely to approve of bans in social venues, and one and a half times more likely to be aged under 30 years.

Since being a socially cued smoker was strongly associated with intention to quit if social venues became smoke-free, further analyses were conducted to investigate the characteristics of this group. Table 4 indicates that compared to others, socially cued smokers were younger, had a lower indication of dependence, had previously tried to quit, and believed there is a safe level of cigarette consumption.

Variables found to be significantly associated with membership of the socially cued smoker category in the bivariate analyses were entered into a logistic regression analysis and 402 cases were included in the final analysis. Table 4 shows a model containing three variables which provide a significant fit to the data $\left(\chi^{2}=54.17, \mathrm{df}=3, \mathrm{p}=0.000\right)$. Compared with smokers not socially cued, socially cued smokers were six times more likely to be under the age of 30 years, two times more likely to believe that there is a safe level of cigarette consumption, and two and a half times more likely to have previously made a quit attempt. Because socially cued smoking and age are highly correlated we did additional analyses relating predictors to age, but found nothing to suggest the results were due to residual confounding.

\section{DISCUSSION}

The findings from this study suggest that the smoking behaviour of a large proportion of smokers, especially young smokers, may be influenced by the imposition of smoke-free policies in bars, nightclubs, and gaming venues. Overall, 69\% of smokers report patronising social venues at least monthly. The majority $(70 \%)$ of smokers who frequently patronise social venues report that they smoke more in these settings (socially cued smokers) and, to the extent that this is true, are likely to reduce their consumption overall if smoking were banned in social venues. Further, a quarter of smokers who frequently patronise social venues reported that they would be more likely to quit smoking altogether if smoking was banned in hotels, licensed bars, gaming venues, and nightclubs. The generalisability of these results needs to be considered in the light of modest response rates. We suspect non-respondents might be more likely to attend social venues (thus being harder to reach for surveying), thereby possibly underestimating the proportion of smokers who attend social venues at least monthly. 
Table 4 Differences between socially cued smokers and not socially cued smokers

\begin{tabular}{|c|c|c|c|c|c|c|}
\hline & $\mathrm{n}$ & Cued $(n=287)$ & $\begin{array}{l}\text { Not cued } \\
(n=122)\end{array}$ & $\mathrm{p}$ Value & Odds ratio $(95 \% \mathrm{Cl})$ & $\mathrm{p}$ Value \\
\hline Percentage of total $\dagger$ & 409 & 70.2 & 29.8 & & & \\
\hline Age $(\%<30$ years $)$ & 406 & 42.5 & 12.4 & $0.000 * * *$ & 6.15 (3.32 to 11.42 ) & $0.000 * * *$ \\
\hline Sex (\% female) & 409 & 51.2 & 44.3 & 0.198 & & \\
\hline Education (\% less) & 408 & 50.3 & 50.8 & 0.931 & & \\
\hline Nicotine dependence (\% yes) & 409 & 45.6 & 59.8 & 0.009 ** & & \\
\hline Made quit attempts (\% yes) & 405 & 82.3 & 72.1 & 0.020 ** & 2.60 (1.47 to 4.59$)$ & $0.001^{* *}$ \\
\hline Safe number of cigarettes ( $\%$ yes) & 409 & 17.1 & 8.2 & 0.019 ** & 2.25 (1.06 to 4.76 ) & $0.034^{* *}$ \\
\hline Bans (\% approve/neither) & 397 & 64.7 & 64.7 & 0.994 & & \\
\hline Stage of change (precontemplation) & 409 & 49.8 & 56.6 & 0.213 & & \\
\hline Likely to quit if bans (more) & 398 & 30.6 & 12.5 & $0.000 * * *$ & & \\
\hline
\end{tabular}

†This differs from the level reported in the text because this is an unweighted figure.

$* * 0<0.05$

$* * * p<0.001$

$\mathrm{Cl}$, confidence interval.

Our estimate of possible quitting at $25 \%$ is higher than that reported by Philpot and colleagues ${ }^{24}$ who found that $11.5 \%$ of people interviewed while queuing for admission to bars and nightclubs (a younger sample than ours) said that adoption of smoke-free policies in hospitality venues "would prompt them to quit". Our question was not as strongly worded, so a greater level of agreement would be expected. Furthermore, younger people in our sample were also more likely to agree that bans would increase likelihood of quitting and this is consistent with Philpot and colleagues' younger sample. Regardless of the exact level, a significant minority of smokers, especially socially cued and younger smokers, believe bans in these venues will help them to quit. It may be the case that smokers act differently in practice, as opposed to what they say they would do in response to smoking bans. Therefore, a priority for subsequent research enquiry would be to conduct studies to determine how much quitting and decline in consumption is actually generated when smoking bans are implemented in such venues. In this respect, observational studies of smoking behaviour in smoking permitted and restricted venues, or cohort studies of how frequent attenders of social venues may change their smoking patterns following the introduction of smoke-free policies, would be informative.

Socially cued smokers are six times more likely to be under the age of 30 than non-socially cued smokers. Thus, the introduction of smoke-free policies in bars, nightclubs, and gaming venues could act as a strategy for preventing the uptake of regular smoking. This possibility has already been raised by some tobacco control advocates who refer to bars and nightclubs as "nicotine classrooms"(G Connolly, personal communication, 2 November 2001). Recent evidence of tobacco industry marketing which targets young people in bars and nightclubs ${ }^{16-18}$ also supports this suggestion.

The group of socially cued smokers we identified are likely to be significant beneficiaries of smoke-free policies in social venues. As a group, they are young and hold beliefs that low levels of smoking are not particularly harmful. As a result it would seem that they think what they are doing is safe. This might be so, in relative terms, if they were not putting themselves at risk of dependence and the subsequent harmful long term use this entails.

The findings from this study suggest that a reason for strong tobacco industry opposition to smoke-free policies in bars, nightclubs, and gaming venues may be because of their concern at the possibility that it will encourage cessation and remove a context where many young people are induced to try smoking. Further research to evaluate the effects of smokefree policies in these venues on smoking behaviour is required.

\section{What this paper adds}

Restrictions on smoking in the workplace and at home reduce levels of smoking in adults. We sought to determine if this may also be the case for recreational venues such as pubs and clubs. A cross sectional survey found that $69 \%$ of smokers report patronising bars, nightclubs or gaming venues at least monthly, and $70 \%$ of those who patronise social venues at least monthly report smoking more in these settings (socially cued smokers). These people are aged under 30 years, have made previous quit attempts, and believe there is a safe number of cigarettes that can be smoked before their health can be affected. Further, 25\% of smokers who frequently patronise social venues report that they would be more likely to quit altogether if there were bans in these venues. These people are likely to be aged under 30 years, contemplating or preparing to quit, and approve of bans in social venues. These findings suggest that smoking restrictions in social venues may reduce smoking prevalence among patrons.

\section{Authors' affiliations}

L Trotter, M Wakefield, Centre for Behavioural Research in Cancer, The Cancer Council Victoria, Victoria, Australia

R Borland, VicHealth Centre for Tobacco Control, The Cancer Council Victoria

\section{REFERENCES}

1 Chapman S, Borland R, Scollo M, et al. The impact of smoke-free workplaces on declining cigarette consumption in Australia and the United States. Am J Public Health 1999;89:1018-23.

2 Owen N, Borland R. Delayed compensatory cigarette consumption after a workplace smoking ban. Tobacco Control 1997;6:131-5.

3 Gilpin $E$, White $M$, Farkas $A$, et al. Home smoking restrictions: which smokers have them and how they are associated with smoking behaviour. Nicotine Tobacco Research 1999;1:153-62.

4 Farkas A, Gilpin E, Distefan J, et al. The effects of household and workplace smoking restrictions on quitting behaviours. Tobacco Control 1999:8:261-5.

5 Biener L, Nyman A. Effects of workplace smoking policies on smoking cessation: results of a longitudinal study. Occup Environ Med 1999;41:1121-7.

6 Borland R, Mullins R, Trotter L, et al. Trends in environmental tobacco smoke restrictions in the home in Victoria, Australia. Tobacco Control 1999:8:266-71.

7 Shiffman S. Relapse following smoking cessation: a situational analysis. Consult Clin Psychol 1982;50:71-86.

8 Borland R, Slip-ups and relapse in attempts to quit smoking. Addictive Behaviors 1990; 15:235-45.

9 Wakefield M, Chaloupka F, Kaufman N, et al. Effect of restrictions on smoking a home, at school, and in public places on teenage smoking: cross section study. BN 2000;321:333-7.

10 Farkas A, Gilpin E, White M, et al. Association between household and workplace smoking restrictions and adolescent smoking. JAMA 2000;284:717-22 
11 Schofield P, Borland R, Hill D, et al. Instability in smoking patterns among school leavers in Victoria, Australia. Tobacco Control 1998; 7: 149-55.

12 Hill D, Borland R. Adults' accounts of onset of regular smoking: Influences of school, work, and other settings. Public Health Reports $1991 ; 106: 181-5$.

13 Schofield PE, Pattison PE, Hill DJ, et al. Youth culture and smoking: Integrating social group processes and individual cognitive processes in a model of health-related behaviours. J Health Psychol (in press).

14 Pierce, JP, Choi WS, Gilpin EA, et al. Validation of susceptibility as a predictor of which adolescents take up smoking in the United States. Health Psychol 1996;15:355-61.

15 Choi WS, Pierce JP, Gilpin EA, et al. Which adolescent experimenters progress to established smoking in the United States. Am J Prev Med 1997; 13:385-91.

16 Katz SK, Lavack AM. Tobacco-related bar promotions: Insights from tobacco industry documents. Tobacco Control 2002;1 1 (supp I):i92-101.
17 Sepe E, Ling P, Glantz S. Smooth moves: bar and nightclub tobacco promotions that target young adults. Am J Public Health 2002;92:414-19.

18 Sepe E, Glantz SA. Tobacco promotions in alternative press: targeting young adults. Am J Public Health 2002;92:75-8.

19 Australian Institute of Health and Welfare. National health data dictionary Version 8.0 AlHW Catalogue No. HWI 18. Australian Institute of Health and Welfare: Canberra 1999

20 Shiffman S. Tobacco "chippers"-individual differences in tobacco dependence. Psychopharmacology (Berl) 1989;97:539-47.

21 Fagerstrom K-O, Schneider N. Measuring nicotine dependence: review of Fagerstrom tolerance questionnaire. J Behav Med 1989;12:159-81.

22 Prochaska JO, DiClemente CC, Norcross JC. In search of how people change. Am Psychol 1992:47:1 102-14.

23 Australian Bureau of Statistics. Population by age and sex, Australian states and territories, Catalogue No. 3201.0, June 2000

24 Philpot S, Ryan S, Torre L, et al. Effect of smoke-free policies on the behaviour of social smokers. Tobacco Control 1999;8:278-81.

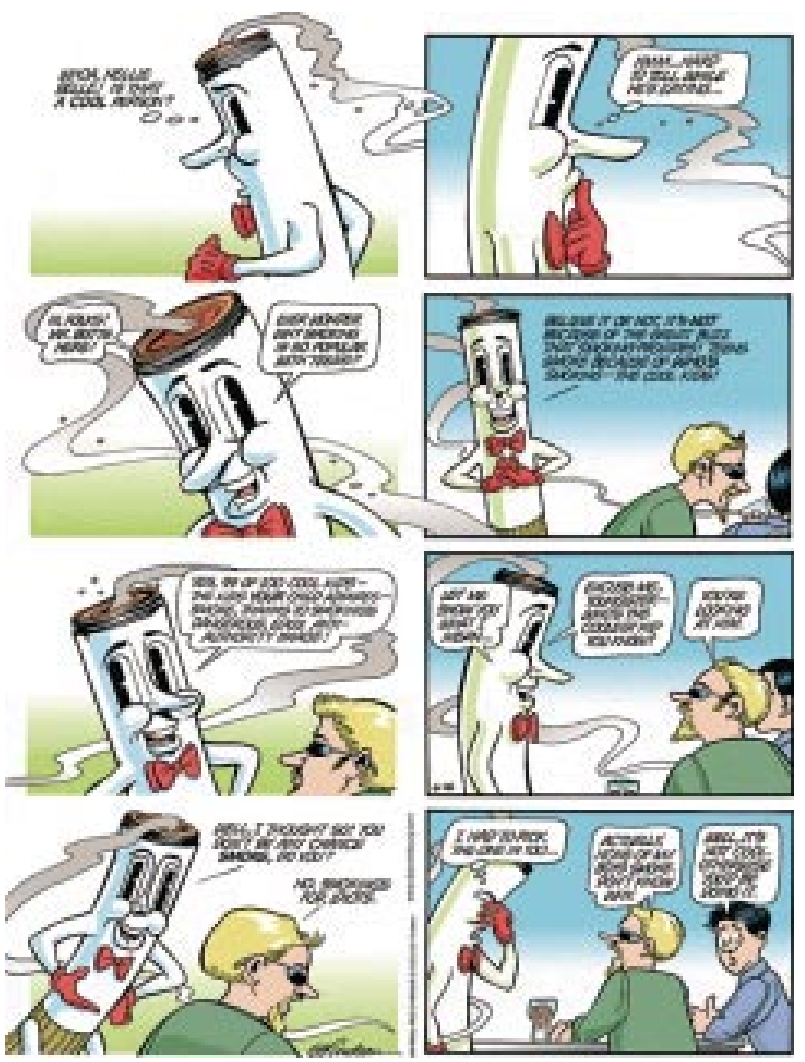

DOONESBURY (C) 2002 G.B. Trudeau. Reprinted with permission of UNIVERSAL PRESS SYNDICATE. All rights reserved 